\title{
Análise de swot do setor florestal na região serrana do estado de Santa Catarina
}

O presente estudo teve como objetivo a análise do setor florestal na Serra Catarinense, através da ferramenta SWOT. Para a coleta dos dados, foi utilizado um questionário semiestruturado de avaliação para a obtenção das opiniões dos entrevistados acerca de questões relevantes que refletem os pontos fortes e fracos, as oportunidades e as ameaças ao setor florestal na região da serra catarinense. Foram entrevistas 6 pessoas diretamente ligadas ao setor florestal na região da serra catarinense, representando os setores público (órgãos ambientais), privado (empresas florestais) e acadêmico (universidades). 0 principal ponto forte da região é 'a elevada produtividade do pinus'; o principal ponto fraco apontado foi 'a liquidez do investimento a longo prazo'; a mais importante oportunidade foi 'o aumento de preço da madeira'; a principal ameaça foi 'a troca de áreas de plantio florestal para culturas anuais ou para criação de gado'.

Palavras-chave: Análise de mercado, economia florestal, Pinus.

\section{Swot analysis of the forest sector in the serra region of the state of Santa Catarina}

The present study aimed to analyze the forestry sector in Serra Catarinense, using the SWOT tool. For data collection, a semi-structured evaluation questionnaire was used to analyze respondents' questions about relevant issues that reflect strengths and weaknesses, such as opportunities and threats to the forest sector in the Santa Catarina region. People linked to the forestry sector in the Santa Catarina region were interviewed, representing the public (environmental agencies), private (forestry companies) and academic (universities) sectors. The main strength of the region is the 'increase of pine'; the main weakness pointed to 'long term net investment'; the most important opportunity was 'the increase in the price of wood' and the main threats was 'the exchange of forest plant areas for cultural crops or cattle raising'

Keywords: Market analysis; Forest economy; Pinus.

Topic: Planejamento, Gestão e Políticas Públicas Ambientais

Reviewed anonymously in the process of blind peer.

Marina Gabriela Cardoso de Aquino iD

Universidade do Estado de Santa Catarina, Brasil

http://lattes.cnpq.br/2168843028631934

http://orcid.org/0000-0002-0160-0804

marinaacardosoo@gmail.com

Jaiton Jaime das Neves Silva

Universidade do Estado de Santa Catarina, Brasil

http://lattes.cnpq.br/1498253171029570

jaitondneves@gmail.com

Gelso Pacheco Neto (D)

Universidade Federal de Santa Maria, Brasil

http://lattes.cnpq.br/4993405331961355

http://orcid.org/0000-0002-0605-6342

gelsopacheconeto@yahoo.com.br
Received: 06/03/2020

Approved: 23/06/2020

Lethiane Borges de Oliveira

Universidade do Estado de Santa Catarina, Brasil

lethiane.borges@yahoo.com.br

Philipe Ricardo Casemiro Soares (iD)

Universidade do Estado de Santa Catarina, Brasil

http://lattes.cnpq.br/7981638557079702

http://orcid.org/0000-0001-9325-738X

philipe.soares@udesc.br
Referencing this:

AQUINO, M. G. C.; SILVA, J. J. N.; PACHECO NETO, G.; OLIVEIRA, L. B.; SOARES, P. R. C.. Análise de swot do setor florestal na região serrana do estado de Santa Catarina. Natural Resources, v.10, n.2, p.68-75 2020. DOI: http://doi.org/10.6008/CBPC2237-9290.2020.002.0009 


\section{INTRODUÇÃO}

A questão florestal no Brasil, em geral, é abordada parcialmente, por meio dos diversos setores que utilizam a madeira como insumo principal - frequentemente o de celulose e papel -, ou sob a perspectiva ambiental (MOREIRA et al., 2017). Observa-se, contudo, que o setor florestal e a atividade de extração de madeira possuem uma dinâmica específica, determinada pela oferta de madeira e pela produtividade das florestas. Ainda que cada um dos produtos florestais possua um mercado próprio, as condições para o seu desenvolvimento estão associadas à base florestal, tornando-os interdependentes (JUVENAL et al., 2002).

De acordo com Oliveira (2016), a crise na indústria madeireira de base extrativista e seus derivados durante as décadas de 1970 a 1980 possibilitou o surgimento dos ramos de papel e celulose, constituindo um dos segmentos industriais mais competitivos do Estado de Santa Catarina. Em vários países do mundo, a atividade madeireira e a cadeia produtiva a ela associada são objeto de investimentos e transações comerciais de elevado valor (JUVENAL et al., 2002). Ainda segundo esses autores, o Brasil, além de possuir a segunda maior cobertura florestal do mundo, desenvolveu tecnologia avançada para a exploração de florestas e para a transformação industrial da madeira.

A cadeia industrial da celulose e papel é a responsável pela maior parte da renda industrial da região sul do Brasil. Os programas de fomento florestal para Pinus e Eucaliptos, criados e implementados pelas principais empresas nas últimas décadas, ampliaram consideravelmente um novo segmento para absorção de mão-de-obra e ofertando uma matéria-prima que substituiu o extrativismo da floresta nativa na região como fonte econômica de renda (OLIVEIRA, 2016).

Ao longo das últimas décadas, o perfil de consumo de madeiras oriundas de reflorestamentos mudou substancialmente em função das restrições de exploração e da disponibilidade de espécies florestais nativas. A cadeia produtiva estendeu-se para as essências de rápido crescimento, plantadas e manejadas (JUVENAL et al., 2002).

De acordo com Moreira et al. (2017), o segmento de florestas plantadas destaca-se no Brasil pelo seu elevado impacto social e econômico. Neste aspecto, áreas com florestas plantadas cumprem papel altamente determinante no abastecimento de matéria-prima para a indústria de transformação, contribuindo diretamente com o desenvolvimento econômico (ACR, 2016).

A grande concentração de plantios de pinus é na Região Sul do Brasil, especificamente os Estados do Paraná e de Santa Catarina, onde as espécies mais plantadas são Pinus elliottii e Pinus taeda, principalmente na Região Serrana (ACR, 2016). O plantio de florestas registrou crescimento de 0,5\% no ano de 2016 em relação ao ano 2015, devido exclusivamente ao aumento das áreas cultivadas com eucalipto (IBA, 2017). A madeira de pinus exerce importante papel na Região Sul no fornecimento de matéria-prima para indústrias de celulose, laminados, painéis compostos e, em alguns polos da Região, como o principal recurso madeireiro das indústrias de móveis (MURARA JUNIOR et al., 2013).

$\mathrm{Na}$ formulação de estratégias, demanda-se do diagnóstico do objeto de planejamento, analisando as oportunidades e ameaças do ambiente e dos pontos fortes e fracos da organização (STEINER, 1979; WRIGHT 
et al., 2000). Diversos autores na literatura científica, utilizam a análise SWOT como ferramenta integrante do planejamento estratégico, atualmente também essa análise foi citada em alguns trabalhos na área florestal (ALVES, 2015).

Portanto, o presente estudo tem como objetivo apontar os pontos fortes, pontos fracos, oportunidades e ameaças presentes no setor florestal da serra catarinense, com em uma pesquisa qualitativa, a ferramenta SWOT, a partir da opinião de diversos públicos relacionados diretamente com o setor florestal no local.

\section{MATERIAIS E MÉTODOS}

Para a coleta dos dados, foi utilizado um questionário semiestruturado de avaliação para a obtenção das opiniões dos entrevistados acerca de questões relevantes que refletem os pontos fortes e fracos, as oportunidades e as ameaças ao setor florestal na região da serra catarinense. O questionário foi confeccionado em uma escala de importância de 10 pontos, conferindo-se valor 1 para a questão menos importante e valor 10 para a questão de maior importância.

A coleta de dados ocorreu no mês de novembro de 2019 e a amostragem foi composta por pessoas diretamente ligadas ao setor florestal na região da serra catarinense. As entrevistas foram aplicadas com profissionais da área florestal, representando os setores público (órgãos ambientais), privado (empresas florestais) e acadêmico (universidades). O grau de importância das variáveis correspondentes às forças, fraquezas, oportunidades e ameaças foi identificado a partir da soma de todas as notas dadas para cada questão considerada.

Os dados foram tabulados em planilha eletrônica utilizando o Microsoft Excel, em que foi realizada uma análise de frequência simples para identificar os itens com maior pontuação e sua relação com a nota total, permitindo a avaliação do grau de importância das variáveis em termos percentuais. Da mesma forma que Angelo et al. (2014), o instrumental analítico seguiu a técnica da análise de Forças, Fraquezas, Oportunidades e Ameaças (SWOT), permitindo ao pesquisador identificar e avaliar as forças e fraquezas de um empreendimento, bem como identificar as oportunidades e as ameaças a que ele está sujeito (Figura 1).

Os pontos fortes e fracos são determinados pelas características internas no setor florestal da região serrana do Estado de Santa Catarina. Já as oportunidades e ameaças são forças ambientais externas não controláveis que podem influenciar no desenvolvimento das atividades no setor de maneira benéfica ou não, dependendo de como são analisados, aproveitadas e/ou evitados. Dessa forma, durante a análise, quando percebido um ponto forte, este deve ser ressaltado e continuado, já um ponto fraco, deve ser controlado ou pelo menos ter seus efeitos reduzidos (ANGELO et al., 2014).

Embora já se conheça a importância da análise SWOT no planejamento estratégico e tomada de decisão, são apontadas algumas inconveniências na utilização dessa ferramenta, como o fato de ela depender de instintos subjetivos, evitar quantificação, não ter poder de prognóstico e nem um suporte teórico concreto para sua validação como uma prática confiável (AGARWAL et al., 2012). Contudo, segundo 
Ulrich (2002), por ser um instrumento simples, a análise SWOT é uma das técnicas mais utilizadas em investigação social, seja na elaboração de diagnósticos, em análises organizacionais ou elaboração de planos.

\section{RESULTADOS E DISCUSSÃO}

\section{Pontos fortes}

A partir da análise das respostas dos entrevistados estabeleceu-se uma classificação dos pontos fortes do setor florestal na Serra Catarinense, Sul do Brasil. Na figura 2 estão apresentadas, em ordem decrescente de importância, as avaliações de dez pontos fortes do setor florestal na região. De maneira geral, a questão referente a 'Elevada produtividade' e 'Produção de diferentes produtos' foram a melhores avaliadas em todos os segmentos analisados, representando, respectivamente, $11,0 \%$ e $10,6 \%$ da ponderação total (520 pontos) atribuída às dez questões avaliadas.

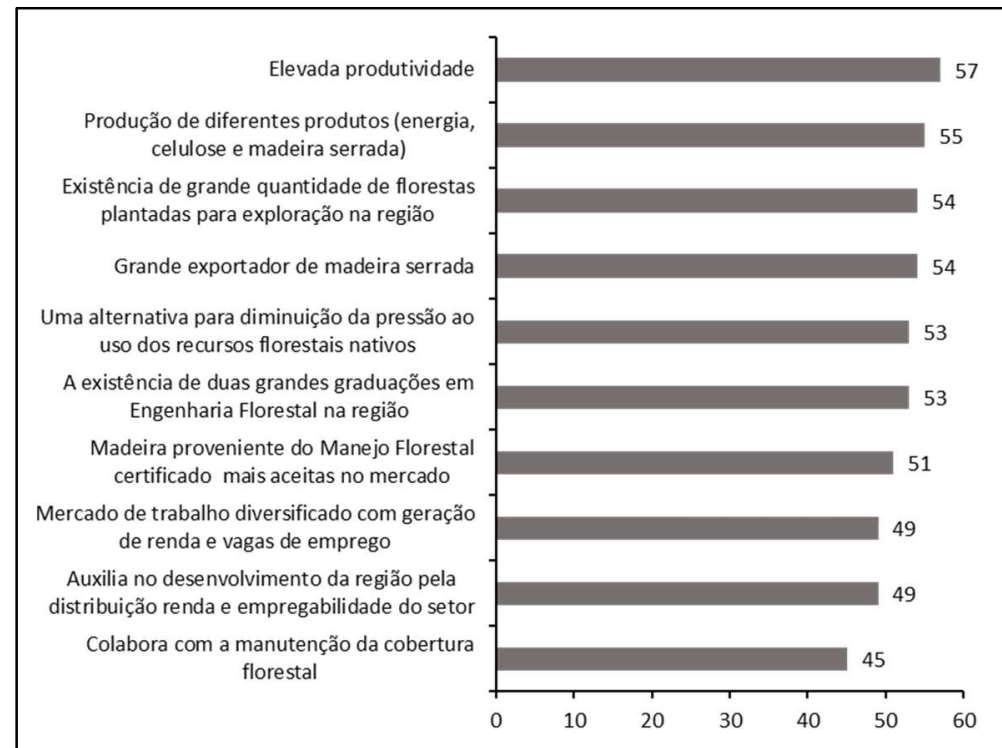

Figura 1: Pontos fortes do setor florestal na Serra Catarinense, Sul do Brasil, segundo os profissionais entrevistados.

Esse percentual aponta que, entre as questões avaliadas, a elevada produtividade atribuída ao alto incremento de Pinus na região, bem como o constante aumento de tecnologias no setor e, consequentemente, a possibilidade de produção de produtos diversos, gerando assim um maior aproveitamento dos indivíduos arbóreos, são os principais pontos fortes do setor florestal na região, conforme a opinião dos entrevistados.

Analisando o cenário nacional, Santa Catarina detém a segunda maior área plantada em pinus (Pinus spp.), onde grande parte da base florestal plantada do estado está concentrada em empresas privadas, garantindo o abastecimento de matéria-prima em seus processos industriais, sendo papel e celulose e painéis de madeira os fins mais comuns (ANDREJOW et al., 2018).

Em segunda e terceira posição estão os pontos fortes referentes a 'Existência de duas grandes universidades com o curso de Engenharia Florestal' e o fato de o Estado ser um 'Grande exportador de madeira serrada', com cerca de 10,2\% e 10,4\% da ponderação total atribuída pelas dez questões avaliadas, respectivamente. Haja vista que a atividade florestal na região apresenta grande potencial de expansão 
(ANDREJOW et al., 2018), os profissionais egressos das universidades serão beneficiados com geração de emprego e renda, e as empresas com um grande número de profissionais qualificados para contratação, aumentando a obtenção líquida de divisas para o país.

A questão 'Colabora com a manutenção da cobertura florestal’ obteve a menor importância dentre as colocações, indicando que este não é considerado um ponto forte do setor florestal. Entretanto, além das diversas funções produtivas, o plantio de árvores exerce importante papel na prestação de serviços ambientais impedindo o desmatamento de hábitats naturais, protegendo assim a biodiversidade (ANDREJOW et al., 2018).

Além disso, com o crescente avanço da agricultura e da indústria madeireira, a cobertura florestal poderá ser reduzida dos atuais 5,3 milhões de quilômetros quadrados, o equivalente a 85\% da área original, para 3,2 milhões de quilômetros quadrados em 2050, o representará 53\% da cobertura original (MARENGO, 2006). Tal fato fortalece ainda mais a importância não só da conservação, mas também da recuperação de áreas florestais como alternativa ao desmatamento e à manutenção da cobertura florestal (ANGELO et al., 2014)

\section{Pontos fracos}

A figura 3 estabelece uma classificação em ordem decrescente de importância dos pontos fracos do setor florestal na Serra Catarinense, de acordo com as 'notas' atribuídas pelos profissionais consultados. De modo geral, os resultados mostraram que questões referentes a 'Liquidez do investimento a longo prazo', a 'Necessidade de investimentos onerosos' e a 'Maior pressão dos órgãos reguladores' foram os mais valorizados pelos entrevistados, recebendo os maiores percentuais de respostas, $14,5 \%, 13,6 \%$ e $13,3 \%$ do percentual total de respostas (345 pontos), respectivamente.

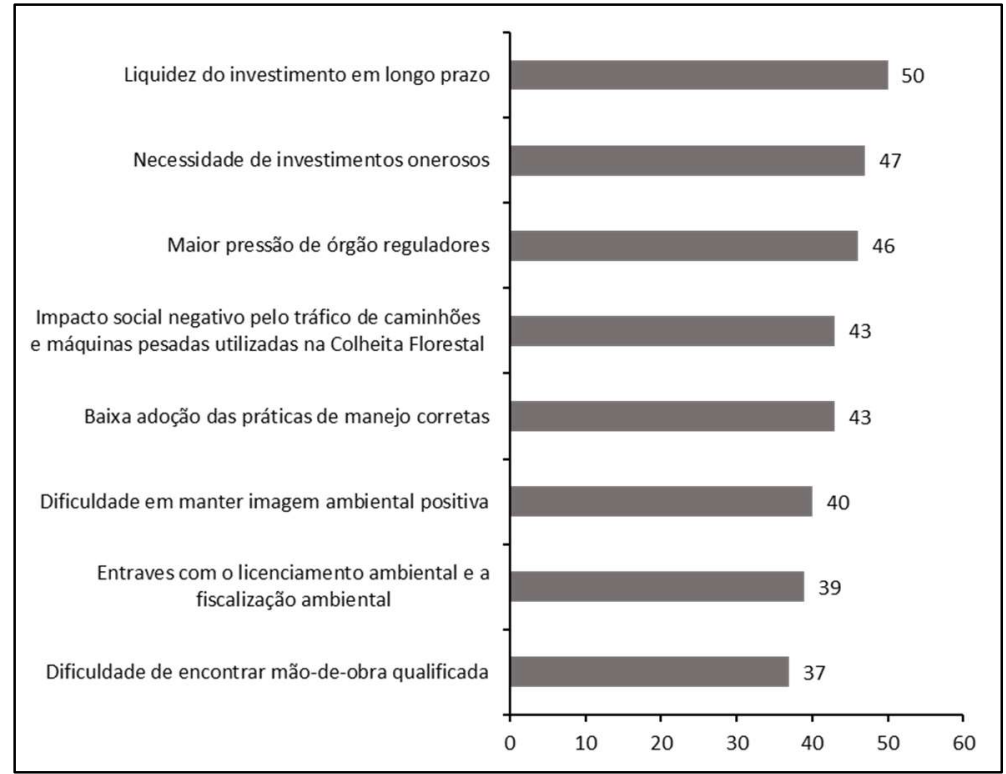

Figura 2: Pontos fracos do setor florestal na Serra Catarinense, Sul do Brasil, segundo os profissionais entrevistados.

Os baixos percentuais das questões 'Dificuldade de encontrar mão de obra qualificada' e 'Entraves com o licenciamento ambiental e fiscalização ambiental' sugerem que os especialistas consultados 
consideram essas questões de menor relevância no contexto das limitações do setor florestal na serra catarinense. Isso pode ser explicado pelo fato de a região possuir muitas oportunidades de formação acadêmica em diversas áreas do setor florestal, como o curso de Engenharia Florestal, em que vários profissionais são colocados anualmente no mercado de trabalho.

Além disso, por se tratar de florestas plantadas de grandes empresas em sua maioria, em que para sua consolidação no mercado e venda de sua matéria-prima são necessários diversos níveis de licenciamento e certificações, não há grandes preocupações quanto a fiscalização, que já é muito presente no setor. Ao contrário de regiões como a Amazônia, em que, segundo Angelo et al. (2014), a falta de instrumentos e mecanismos eficazes e de recursos humanos e financeiros inibem as ações do governo na fiscalização da imensa área da floresta amazônica, para impedir a retirada predatória da madeira, ou mesmo mitigar ações que degradam a floresta.

\section{Oportunidades}

Na figura 4 estão sumarizados os resultados da avaliação das principais questões referentes às oportunidades do setor florestal na Serra Catarinense. A partir das ponderações atribuídas pelos especialistas, estabeleceu-se um ordenamento decrescente de preferência das questões avaliadas. Em todos os segmentos analisados, o 'Aumento do preço da madeira' e a 'Redução de alíquotas de impostos como IPI e ICMS' foram, entre as quatro questões avaliadas, as que alcançaram os maiores percentuais de respostas, com, respectivamente, $28,4 \%$ e $27,9 \%$ do total de respostas (183 pontos).

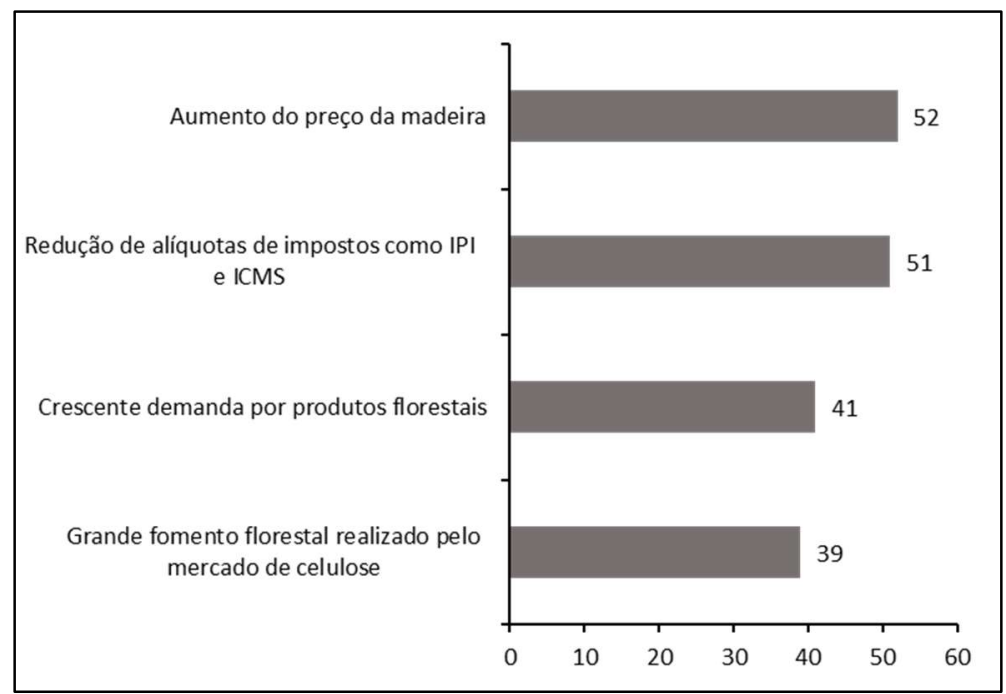

Figura 3: Oportunidades do setor florestal na Serra Catarinense, Sul do Brasil, segundo os profissionais entrevistados.

A aptidão da região sul para a implantação de florestas plantadas, principalmente por empresas produtoras de produtos madeiros é destacada pelo alto grau de aproveitamento da matéria-prima por meio de produtos florestais madeireiros (ANDREJOW et al., 2018). A variedade de produtos advindos dessa atividade econômica permite que estes possam ser comercializados em qualquer nível de processamento, muitas vezes sem terem que passar por nenhuma etapa industrial. A crescente demanda de matéria-prima 
proveniente da madeira na Região Sul gera constantemente um aumento no preço das toras, o que acaba sendo refletido no custo final dos produtos acabados (MURARA JUNIOR et al., 2013).

\section{Ameaças}

Com base nas opiniões dos entrevistados, estabeleceu-se um ordenamento preferencial das principais ameaças do setor florestal no Estado de Santa Catarina, Sul do Brasil, conforme destacado na figura 5. De modo geral, os resultados mostraram que a 'A troca de áreas de plantio florestal para culturas anuais ou para criação de gado' e a 'Instabilidade econômica' e 'Manifestação de pragas nos plantios' foram as questões mais valorizadas pelos especialistas consultados, alcançando 18,7\% e 17,6\% para os dois últimos, respectivamente. Entretanto, os resultados sugerem que a 'Pouca fiscalização no mercado de madeira ilegal' representa uma baixa ameaça ao setor florestal na região (15,0\% do total das respostas).

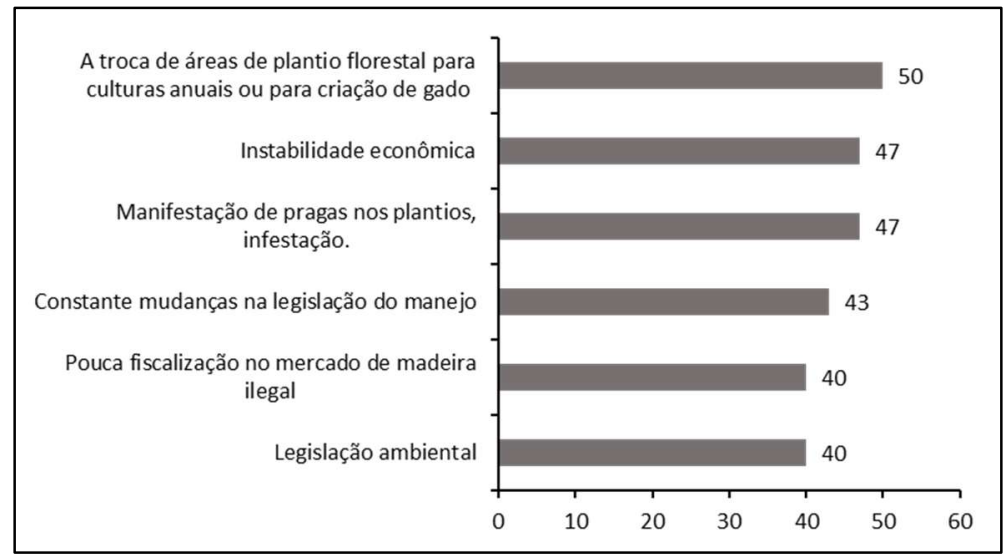

Figura 4: Ameaças do setor florestal na Serra Catarinense, Sul do Brasil, segundo os profissionais entrevistados.

A ascensão dos plantios de Pinus spp. na região, beneficia a disseminação de doenças, as quais acarretam prejuízos aos silvicultores, especialmente em condições favoráveis à sua ocorrência. Entre as principais doenças de Pinus que mais chamam a atenção pelo potencial de perdas para a silvicultura estão as podridões de raízes, a seca de ponteiros, a armilariose, que se caracterizam principalmente pela dificuldade de estabelecimento de medidas de controle efetivas (AUER et al., 1997).

A 'Pouca fiscalização no mercado de madeira ilegal' foi uma das questões menos relevantes quanto as ameaças no setor florestal na serra catarinense segundo os entrevistados. Ainda que, segundo Veríssimo (2005), a madeira retirada da floresta ilegalmente possui preços bastante reduzidos no mercado comparada com aquela produzida a partir de planos de manejo, pode não ser considerada uma ameaça na região por não haver tantos entraves com a fiscalização e certificação ambiental, inclusive foram apontados como pontos fracos de pouca preocupação no presente trabalho.

Além disso, o comércio de madeira ilegal ocorre, principalmente, em áreas com espécies nativas raras, que alcançam preços exorbitantes no mercado, como é o caso da região Amazônica, onde esta é uma preocupação constante, pois essa exploração predatória causa uma competição desleal entre a madeira ilegal e a madeira de manejo florestal, pois a primeira é mais lucrativa, no curto prazo. 


\section{CONCLUSÕES}

Os principais pontos fortes do setor florestal na região serrana do Estado de Santa Catarina foram: Elevada produtividade e a Possibilidade de produção de produtos diversos. Os principais pontos fracos ressaltados foram: Liquidez do investimento a longo prazo, a Necessidade de investimentos onerosos e a Maior pressão dos órgãos reguladores.

Quanto ao ambiente externo com as principais oportunidades elencadas no estudo foram: Aumento do preço da madeira e a Redução de alíquotas de impostos como IPI e ICMS. E como ameaças, as que obtiveram maior destaque no estudo foram: A troca de áreas de plantio florestal para culturas anuais ou para criação de gado e a Instabilidade econômica e Manifestação de pragas nos plantios.

Conclui-se pelo presente estudo que o cenário analisado no caso o setor florestal na região serrana do estado de Santa Catarina tem uma estabilidade e consolidação de mercado proveniente de décadas por ter na região diversos pontos fortes como: uma cadeia de indústria florestal, alta produtividade florestal. No entanto, na atualidade existe como ameaças ao setor florestal a concorrência das culturas anuais como soja e a criação de gado pelo seu valor agregado e também por ser uma fonte anual de rendimentos com uma maior liquidez de investimento a curto prazo.

\section{REFERÊNCIAS}

ACR. Associação Catarinense de Empresas Florestais. Anuário Estatístico de Base Florestal para o Estado de Santa Catarina 2016. Lages: ACR, 2016.

AGARWAL, R.; GRASSL, W.; PAHL, J.. Meta SWOT: introducing a new strategic planning tool. Journal of Business Strategy, Bingley, v.33, n.2, p.12-21, 2012.

ALVES, F. L.. Contribuições do planejamento estratégico para a formulação de proposta de política florestal sustentável para o Estado do Rio de Janeiro. Trabalho de Conclusão de Curso (Graduação em Gestão Florestal), Universidade Federal do Paraná, Curitiba, 2015.

ANDREJOW, G. M. P.; PEDRASSANI, D.; TUSSULINI, F.; ANGELO, A. V.; TAMBARUSSI, E. V.; AUER, C. G.. Planalto Norte Catarinense: considerações sobre o setor florestal e a eucaliptocultura. Revista de Desenvolvimento Regional em Debate, v.8, n.2, p.143-168, 2018.

ANGELO, H.; SILVA, J. C.; ALMEIDA, A. N.; POMPERMAYER, R. S.. Análise estratégica do manejo florestal na Amazônia brasileira. Revista Floresta, Curitiba, v.44, n.3, p.341 - 348, 2014.

AUER, C. G.; JUNIOR, A. G.. Doenças registradas em Araucaria angustifolia e Pinus spp. nos Estados do Paraná e de Santa Catarina. EMBRAPA, 1997.

JUVENAL, T. L.; MATTOS, R. L. G.. O setor florestal no Brasil e a importância do reflorestamento. BNDES Setorial, Rio de Janeiro, n.16, p.3-30, 2002.
MARENGO, J. A.. Mudanças climáticas globais e seus efeitos sobre a biodiversidade: caracterização do clima atual e definição das alterações climáticas para o território brasileiro ao longo do século XXI. Brasília: MMA, 2006.

MOREIRA, J. M. M. A. P.; SIMIONI, F. J.; OLIVEIRA, E. B. Importância e Desempenho das Florestas Plantadas No Contexto do Agronegócio Brasileiro. Revista Floresta, Curitiba, v.47, n.1, p.85-94, 2017.

MURARA JUNIOR, M. I. M.; ROCHA, M. P.; TRUGILHO, P. F.. Estimativa do Rendimento em Madeira Serrada de Pinus para Duas Metodologias de Desdobro. Revista Floresta e Ambiente, v.20, n.4, p.556-563, 2013.

OLIVEIRA, M. A.. Mundo rural (economia, trabalho e migrações) na Serra Catarinense/Brasil: Elementos para discussão da centralidade do trabalho agrícola no meio rural no contexto de sua reestruturação produtiva na atualidade. Jornal de Políticas Educacionais, v.10, n.20, p.106-117, 2016.

ULRICH, S.. MAPA: Manual de Planejamento e Avaliação de Projetos. Cascais: Principia, 2002.

VERÍSSIMO, A.. Manejo Florestal Empresarial na Amazônia Brasileira: restrições e oportunidades para a adoção de boas práticas de manejo. Belém: Cifor-Imazon-EMBRAPA-FFT, 2005.

A CBPC - Companhia Brasileira de Produção Científica (CNPJ: 11.221.422/0001-03) detém os direitos materiais desta publicação. Os direitos referem-se à publicação do trabalho em qualquer parte do mundo, incluindo os direitos às renovações, expansões e disseminações da contribuição, bem como outros direitos subsidiários. Todos os trabalhos publicados eletronicamente poderão posteriormente ser publicados em coletâneas impressas sob coordenação da Sustenere Publishing, da Companhia Brasileira de Produção Científica e seus parceiros autorizados. Os (as) autores (as) preservam os direitos autorais, mas não têm permissão para a publicação da contribuição em outro meio, impresso ou digital, em português ou em tradução. 